\title{
Deflection and Maximum Load of Microfiltration Membrane Sieves Made with Silicon Micromachining
}

Cees van Rijn, Michiel van der Wekken, Wietze Nijdam, and Miko Elwenspoek

\begin{abstract}
With the use of silicon micromachining, an inorganic membrane sieve for microfiltration has been constructed having a silicon nitride membrane layer with thickness typically $1 \mu \mathrm{m}$ and perforations typically between $0.5 \mu \mathrm{m}$ and $10 \mu \mathrm{m}$ in diameter. As a support a $\langle 100\rangle$-silicon wafer with openings of $1000 \mu \mathrm{m}$ in diameter has been used. The thin silicon nitride layer is deposited on an initially dense support by means of a suitable chemical vapor deposition method (LPCVD). Perforations in the membrane layer are obtained with use of standard photo lithography and reactive ion etching (RIE). The deflection and maximum load of the membrane sieves are calculated in a first approximation. Experiments to measure the maximum load of silicon-rich silicon nitride membranes have confirmed this approximation. [215]
\end{abstract}

Index Terms - Filtration membranes, micro filtration, membrane filtration, membrane strength, membrane deflection.

\section{INTRODUCTION SIEVE FILTERS}

$\mathbf{S}$ IEVE filters are characterized by thin membrane layers with uniformly sized pores, and for most applications, the membrane layer is sustained by a support. Until now, lithographic techniques have not been used for the construction of microfiltration membrane layers made of such inorganic materials as silicon nitride and silicon [1].

Inorganic membranes, and in particular ceramic membranes [2], have a number of advantages above polymeric membranes, such as they are stable at high temperature, relatively inert to chemicals, applicable at high pressures, easy to sterilize, and recyclable. However, they have not been used extensively because of their high costs and relatively poor control in pore size distribution (see Fig. 1). Also, the effective membrane layer is very thick in comparison to the mean pore size (typically 50-1000 times), which results in a reduced flow rate.

A composite filtration membrane having a relatively thin filtration or sieving layer with a high pore density and a narrow pore size distribution on a macroporous support will show good separation behavior and a high flow rate (see Fig. 2). The support contributes to the mechanical strength of the total composite membrane. The openings in the support

Manuscript received June 12, 1996; revised October 24, 1996. Subject Editor, N. de Rooji.

The authors are with the MESA Research Institute, Department of Electrical Engineering (TDM), University of Twente, NL 7500 AE Enschede, The Netherlands.

Publisher Item Identifier S 1057-7157(97)02114-8.

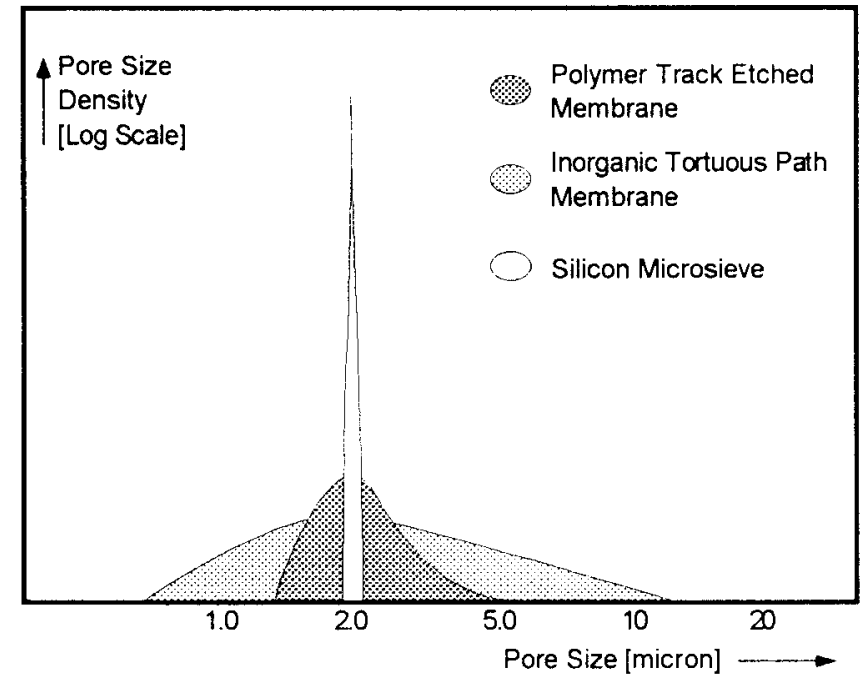

Fig. 1. Pore size distribution of various membrane filters.

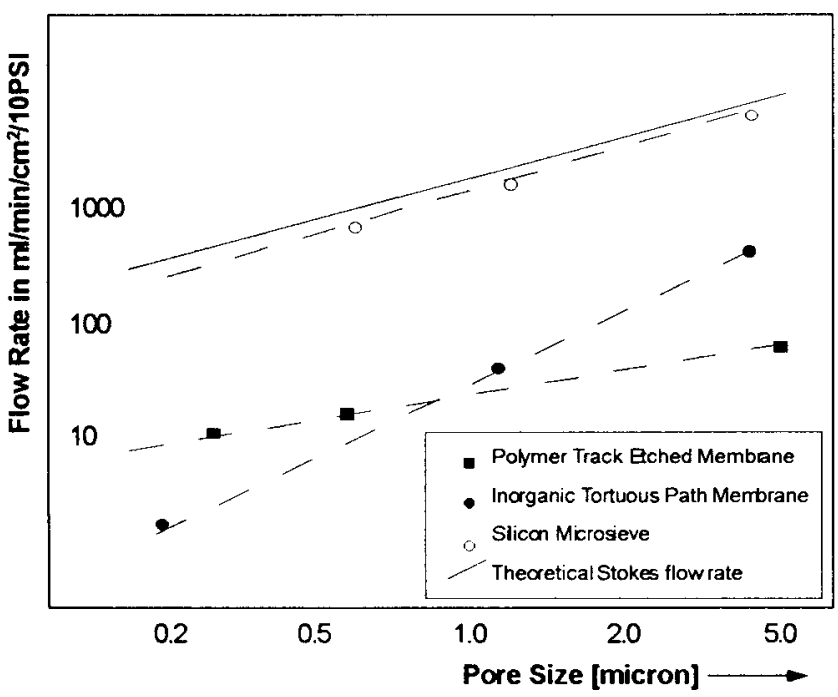

Fig. 2. Clear water flux of various membrane filters.

should be made as large and numerous as possible in order to maintain the flow rate of the membrane layer and to reduce the interaction of the support with the fluid. An established use of inorganic membranes with very thin membrane layers, 
in particular microsieves with high flow rates, will result in an energy- and cost-saving separation technology for present and future innovative applications, like micro liquid handling, modular fluidic systems or micro total analysis systems [3].

\section{CONSTRUCTION}

Figs. 3-6 show in cross section subsequent stages of a process for production of the membrane consisting of a support and a membrane layer. On a surface of the support 1, a single crystalline 3 -in $\langle 100\rangle$-silicon wafer with thickness of $380 \mu \mathrm{m}$ a layer 2 of silicon nitride with thickness 1 $\mu \mathrm{m}$ is deposited by means of chemical vapor deposition (CVD). This layer 2 is formed by reaction of dichloresilane $\left(\mathrm{SiH}_{2} \mathrm{Cl}_{2}\right)$ and ammonia $\left(\mathrm{NH}_{3}\right)$ at elevated temperature $850{ }^{\circ} \mathrm{C}$ and low pressure (LPCVD). Silicon-rich silicon nitride (nonstochiometric) with reduced internal stress properties may be grown in an excess dichloresilane (70 $\mathrm{SiH}_{2} \mathrm{Cl}_{2} / 18 \mathrm{NH}_{3}$ at $850{ }^{\circ} \mathrm{C}$ ) ambient. On the silicon nitride layer 2 a photosensitive lacquer layer 3 is formed by spin coating at 4000 r.p.m., as in Fig. 3 (in this example Shipley Europe Resist S1818 with a thickness of $1.8 \mu \mathrm{m}$ ). The lacquer layer 3 is then exposed to a mask pattern with the use of a suitable ultra violet source, here with a Karl Süss projection system using proximity projection. The mask pattern is made of a square field of $10 \times 10$ membrane areas of $1000 \mu \mathrm{m} \times 1000 \mu \mathrm{m}$. The membrane areas are separated at spacings of $200 \mu \mathrm{m}$. Each membrane area has $100 \times 100$ circular perforations with diameter $4 \mu \mathrm{m}$. The mutual distance between the centre of the perforations is $10 \mu \mathrm{m}$. After exposure the lacquer layer 3 is developed for $45 \mathrm{~s}$ in a diluted $\mathrm{NaOH}$ solution giving a mask pattern in the lacquer layer 4 on the silicon nitride layer 2 (see Fig. 4). In the silicon nitride layer 2 , the mask pattern is then etched by means of $\mathrm{CHF}_{3} / \mathrm{O}_{2}$ reactive ion etching at $10 \mathrm{mTorr}$ and $75 \mathrm{~W}$ for $15 \mathrm{~min}$, forming the perforations 5 in the membrane layer (Fig. 5). Next, perforations 6 of $1000 \mu \mathrm{m} \times 1000 \mu \mathrm{m}$ are etched using the backside silicon nitride layer 2 as an etch mask in the silicon support 1 with an anisotropic etch along the $\langle 111\rangle$ planes with a $10 \% \mathrm{KOH}$ solution at $70{ }^{\circ} \mathrm{C}$ until the membrane layer is reached (Fig. 6).

\section{DEFLECTION AND MAXIMUM LOAD of a Clamped Rectangular MEMBrane}

The deflection curve $w(x)$ of a rectangular plate with dimension $l \cdot b \cdot h$ clamped at two edges $x=0, l$ stretched by an axial distributed force $S$ and uniformly loaded under a pressure $q$ is given by the well-known differential equation

$$
D \frac{d^{4} w(x)}{d x^{4}}-S \frac{d^{2} w(x)}{d x^{2}}=q
$$

with flexural rigidity

$$
D=\frac{E h^{3}}{12\left(1-\nu^{2}\right)}
$$

( $\nu=$ Poisson's ratio, $E=$ Young's modulus).

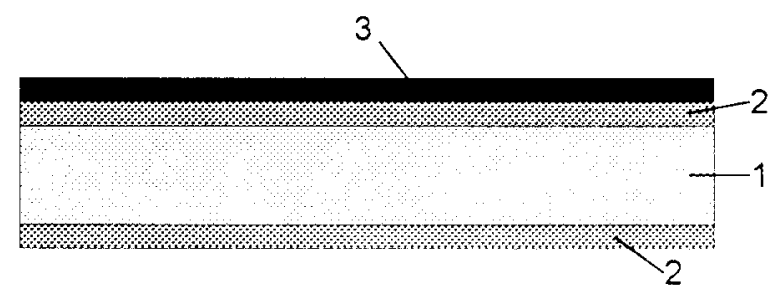

Fig. 3. Process step of the microseive.

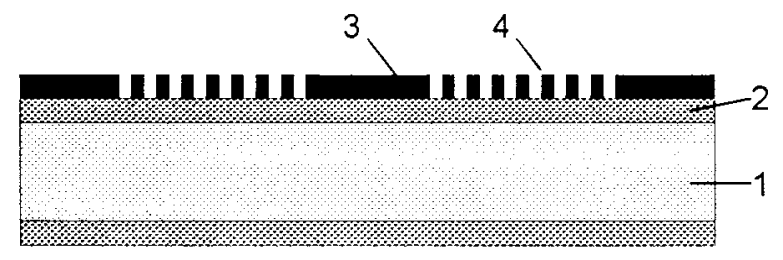

Fig. 4. Process step of the microseive.

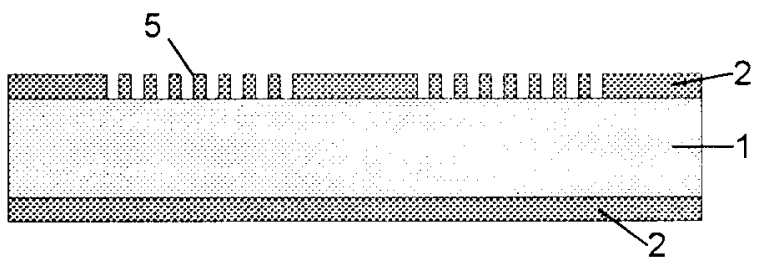

Fig. 5. Process step of the microseive.

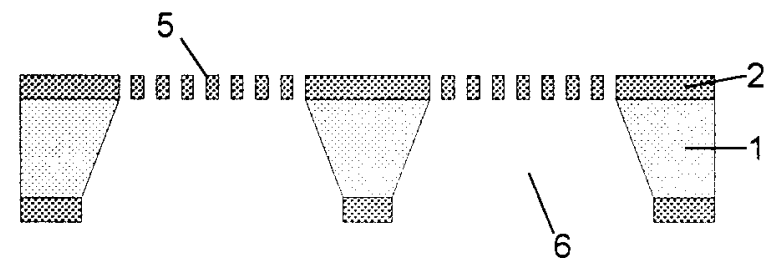

Fig. 6. Process step of the microseive.

The general solution symmetrical in $x=l / 2$ following Timoshenko [4] is given by

$$
\begin{aligned}
w= & \frac{q l^{4}}{16 u^{3} D \tanh u} \\
& \times\left\{\frac{\cos h\left[u\left(1-\frac{2 x}{l}\right)\right]}{\cosh u}-1\right\}+\frac{q l^{2}(l-x) x}{8 u^{2} D}
\end{aligned}
$$

with definition $u^{2}=S l^{2} / 4 D$.

The deflection near the center of the membrane is mainly determined by the parabolic term, whereas the deflection near the edge of the membrane is mainly determined by the first term. 


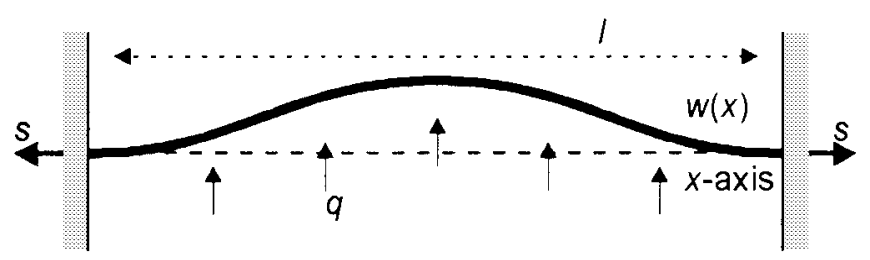

Fig. 7. Deflection $w(x)$ of a two-edge, clamped membrane stretched with axial distributed force $S$ and uniformly loaded with pressure $q$.

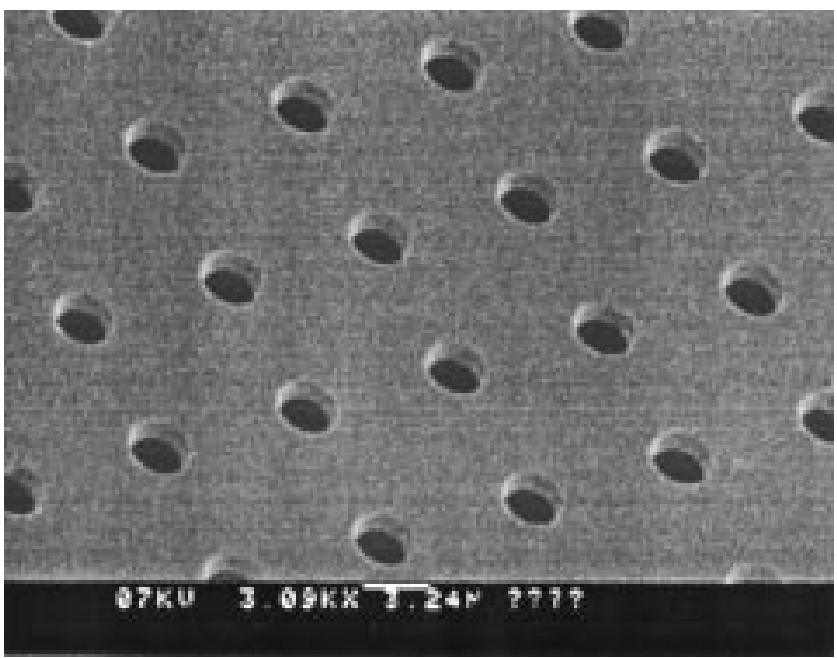

Fig. 8. SEM picture of microsieve with LPCVD silicon nitride layer $\pm 1 \mu \mathrm{m}$ in thickness and perforations $\pm 3 \mu \mathrm{m}$ in diameter.

The points of inflection $\left(d^{2} w / d x^{2}=0\right)$ of the deflection curve are determined by the dimensionless parameter $u$. For small values $u \ll 1$ the inflection points are almost independent of $u$ and given by

$$
x=l / 2 \pm \frac{l}{2 \sqrt{3}} .
$$

At a large axial force $S$ the points of inflection will move toward the edges. For $u \gg 1$ these points are located at

$$
x=l / 2 \pm\left(l / 2-\frac{l \ln u}{2 u}\right) .
$$

For very thin plates or membranes $u$ will be already large at moderately values of the axial force $S$.

The general solution is fully determined by the constants $D, S$, and $q$. For large deflections the axial force $S$ will increase due to elastic extension $\Delta l$ of the plate clamped between the edges. We will show that $S$ may be expressed as a simple function of $D, q, l$, and $\nu$ in the limit for large values of $u$. In this limit $S$ is still a constant (dependent only on other constants) and is independent on $x$, so the deflection curve $w(x)$ is still a solution of the differential equation.

The increment $\Delta S$ is related to the increment $\Delta l$

$$
\begin{aligned}
\Delta l & =\varepsilon l=\frac{\Delta S\left(1-\nu^{2}\right) l}{h E} \\
& =\int_{0}^{1} d l-l=\int_{0}^{1} \sqrt{d x^{2}+d w(x)^{2}}-l .
\end{aligned}
$$

It can be shown that the latter term is almost independent on $w(x)$ for all type of deflections under the condition $d w(x) / d x \ll 1$, or $w_{\max } \ll l . \Delta l$ Scales then with $w_{\max }^{2} / l$. For a parabolic deflection curve we have $\Delta l=(8 / 3) w_{\max }^{2} / l$. Using

$$
u^{2}=(S+\Delta S) l^{2} / 4 D=u_{0}^{2}+\Delta S l^{2} / 4 D
$$

one obtains

$$
\Delta l=\frac{4 D\left(u^{2}-u_{0}^{2}\right)\left(1-\nu^{2}\right) l}{l^{2} h E}=\frac{8}{3} \frac{w_{\max }^{2}}{l} .
$$

Alternatively $w_{\max }$ is determined by the deflection curve, for $u \gg 1$ at $x=l / 2, w_{\max }=q l^{4} / 32 u^{2} D$.

For large deflections the inflection parameter $u_{0}$ related to the initial axial force density $S$ may be neglected, i.e., $u \gg u_{0}$, hence the following relation using (2) and (7) is found for $u$ :

$$
u_{u \gg 1}^{6}=\frac{9\left(1-\nu^{2}\right)^{2} q^{2} l^{8}}{8 E^{2} h^{8}} .
$$

The maximum deflection $w_{\max }$ at $x=l / 2$ is given by

$$
w_{\max }=\frac{q l^{4}}{\bar{\gg} 132 D u^{2}}=0,36 l \sqrt[3]{\frac{q l\left(1-\nu^{2}\right)}{E h}} \nu=0.250,35 l \sqrt[3]{\frac{q l}{E h}} .
$$

The constant tensile stress in the plate is then estimated for large values of $u \gg 1$

$$
\begin{aligned}
\sigma_{\text {tensile }}=\frac{S}{h} & =\frac{4 u^{2} D}{h l^{2}}=\frac{E u^{2}}{3\left(1-\nu^{2}\right)}\left(\frac{h}{l}\right)^{2} \\
& =0,37 \sqrt[3]{\frac{q^{2} l^{2} E}{h^{2}}} \\
\nu=0.25 & =1.25
\end{aligned}
$$

and the maximum bending stress at the edge of the membrane is estimated by

$$
\begin{aligned}
\sigma_{\text {bend }}=\frac{E}{1-\nu^{2}} \frac{d^{2} w}{d x^{2}} z & =\frac{3 q}{\substack{u \gg 1 \\
x=0 \\
z=h / 2}}\left(\frac{l}{h}\right)^{2} \\
& =\overline{\tanh } u 1,47 \sqrt[3]{\frac{q^{2} l^{2} E}{h^{2}}}
\end{aligned}
$$

The above expressions are valid for a rectangular plate clamped at two edges and may be valid for a thin membrane plate under a substantial load at large deflections $w_{\max } / h \gg 1$. Equation 10 gives a good scaling relation for $\sigma_{\text {tensile }}$ for all type of deflections under the condition $w_{\max } \ll l$, whereas (11) gives a similar scaling relation for $\sigma_{\text {bend }}$ at the edge of the membrane.

The actual case to be considered here is a rectangular membrane clamped at all four edges. With the principle of virtual work Timoshenko [5] has calculated the deflection $w_{0}$ of the centre of a square membrane clamped at four edges:

$$
w_{0}=0.802 a \sqrt[3]{\frac{q a}{E h}} \underset{a=l / 2}{=} 0.318 l \sqrt[3]{\frac{q l}{E h}}
$$

and corresponding tensile stress $\sigma_{0}$ in the middle of the membrane

$$
\begin{aligned}
\sigma_{0}=\frac{E}{1-\nu} 0.462 \frac{w_{0}^{2}}{a} \underset{\nu}{\nu} & =0.250 .396 \sqrt[3]{\frac{q^{2} a^{2} E}{h^{2}}} \\
& =0.29 \sqrt[3]{\frac{q^{2} l^{2} E}{h^{2}}}
\end{aligned}
$$


TABLE I

The Maximum Load of Membranes (with $l=1 \mathrm{~mm}, h=1 \mathrm{~mm}$ ). Values for $E, \sigma_{\text {yield }}$, $q_{\mathrm{u}}$ timate Are Bulk Values from Timoshenko Mechanics of Materials, Except the Values for $S_{\text {rich }} N_{\text {poor }}[9]$

\begin{tabular}{|c|c|c|c|c|c|c|c|c|c|}
\hline Material & {$\left[\begin{array}{c}E \\
{[\mathrm{G} P a]}\end{array}\right.$} & $\begin{array}{c}\sigma_{\text {yield }} \\
{[\mathrm{M} \mathrm{Pa}]}\end{array}$ & $\begin{array}{l}\sigma_{\text {uftimate }} \\
{[\mathrm{M} \mathrm{Pa}]}\end{array}$ & $\begin{array}{l}q_{\text {tens }} \\
\text { tens. } \\
\text { [bar] }\end{array}$ & $\begin{array}{c}q_{\text {yield }} \\
\text { tens.+bend. } \\
\text { [bar] }\end{array}$ & $\mid \begin{array}{c}q_{\text {break }} \\
\text { calculated } \\
\text { [bar] }\end{array}$ & $\begin{array}{c}q_{\text {break }} \\
\text { measured } \\
\text { [bar] }\end{array}$ & $u$ & $\begin{array}{c}\text { Bending } \\
\text { Point } \\
\text { from edge } \\
{[\mu \mathrm{m}]}\end{array}$ \\
\hline$\overline{\mathrm{Al}}$ & 70 & 50 & 70 & 0.1 & 0.01 & $>0.21$ & 1.3 & $\begin{array}{c}> \\
28.7\end{array}$ & $<58$ \\
\hline $\mathrm{Ni}$ & 210 & 400 & 500 & 1.10 & 0.10 & $>1.1$ & & $>74$ & $<29$ \\
\hline $\mathrm{Cu}$ & 110 & 330 & 380 & 1.14 & 0.10 & $>1.14$ & 5.3 & $>93$ & $<24$ \\
\hline $\begin{array}{l}\text { Stainless } \\
\text { Steel }\end{array}$ & 200 & 450 & 800 & 1.35 & 0.12 & $>1.35$ & & $>81$ & $<27$ \\
\hline $\mathrm{Ti}$ & 110 & 400 & 500 & 1.54 & 0.14 & $>1.53$ & 1.5 & $>103$ & $<22$ \\
\hline $\bar{W}$ & 360 & 2500 & 2500 & 13.3 & 1.2 & 1.2 & & 64 & 32 \\
\hline $\mathrm{Si}_{\text {rich }} N_{\text {poor }}$ & 290 & 4000 & 4000 & 30.1 & 2.7 & 2.7 & 2.5 & 89 & 25 \\
\hline & 190 & 7000 & 7000 & 86 & 7.8 & 7.7 & & 146 & 17 \\
\hline $\mathrm{Al}_{2} \mathrm{O}_{3}$ & 530 & 15400 & 15400 & 168 & 15.2 & 14.9 & & 130 & 19 \\
\hline$\overline{\mathrm{Si}_{3} \mathrm{~N}_{4}}$ & 385 & 14000 & 14000 & 171 & 15.5 & 15.4 & & 145 & 17 \\
\hline $\mathrm{SiO}_{2}$ & 73 & 8400 & 8400 & 182 & 16.5 & 16.4 & & 258 & 11 \\
\hline $\mathrm{SiC}$ & 700 & 21000 & 21000 & 233 & 21.0 & 20.9 & & 132 & 18 \\
\hline Diamond & 1035 & 53000 & 53000 & 768 & 69.4 & 68.9 & & 172 & 15 \\
\hline
\end{tabular}

The values for $w_{0}$ and $\sigma_{0}$ are reasonably well corresponding with the values found for $w_{\max }$ and $\sigma_{\text {tensile }}$ for the two clamped case. The value for the maximum deflection $w_{\max }$ in the two edge clamped case is slightly larger than in the four edge clamped case due to the extra constraint, thus limiting the value of the deflection in the middle of the membrane.

Because $\sigma_{\text {bend }}$ and $\sigma_{\text {tensile }}$ scale identical at the edge of the membrane ${ }^{1}[6]$, it is assumed that the ratio between both stresses remains unchanged for the two clamped and four clamped case, Moreover, in the four clamped case the maximum stress [7] is found near the middle of the edges. The deflection curve will resemble there the most the two clamped case. The total tensile stress at the edge is the addition of the constant tensile stress due to stretching and the bending stress near the middle of the edge

$$
\sigma_{\text {total }}=\sigma_{\text {tensile }}+\sigma_{\text {bend }} \underset{\substack{u \gg 1 \\ x=0}}{=} 0.29(1+1.47 / 0.37) \sqrt[3]{\frac{q^{2} l^{2} E}{h^{2}}} .
$$

In above approximate equation (14) internal stresses in the materials are not taken into account. It is well known that stochiometric silicon nitride membranes fracture at relatively low pressures due to high intrinsic tensile stress of the order of $1 \mathrm{GPa}$ [8]. The intrinsic tensile stress $\sigma_{0}$ in a siliconrich silicon nitride membrane with thickness $1 \mu \mathrm{m}$ is much smaller [9], ranging from $0.8 \cdot 10^{8}$ to $1.6 \cdot 10^{8} \mathrm{~Pa}$. The maximum tensile stress $\sigma_{\text {yield }}$ before rupture occurs is for silicon-rich silicon nitride [10] about $4.0 \cdot 10^{9} \mathrm{~Pa}$. The intrinsic tensile stress may according to the above safely be neglected in calculating the maximum pressure $q_{\text {break }}$ before fracture occurs $\left(u \gg u_{0}\right)$. Using Young's modulus $E$ for silicon nitride $2.9 \cdot 10^{11} \mathrm{~Pa}$ and $\nu=0.25$ we find $q_{\mathrm{break}}=2.7$ bar for a dense square silicon nitride membrane with width $l=1000 \mu \mathrm{m}$. The

\footnotetext{
${ }^{1}$ For round membranes similar scaling relations for $\sigma_{\text {bend }}$ and $\sigma_{\text {tensile }}$ have been proposed at the edge of the membrane for large deflections by $\mathrm{M}$. P. Di Giovanni.
}

inflection parameter then is $u=40$. The inflection points of the membrane are then located at $25 \mu \mathrm{m}$ from the edge.

In Table I some theoretical estimates for the maximum load $q_{\text {break }}$ have been given for some inorganic materials, including some metals.

For nonductile inorganic materials, the ultimate stress $\sigma_{\text {ultimate }}$ at which the membrane breaks at pressure $q_{\text {break }}$ coincides with the pressure $q_{\text {yield }}$ when the stress in the membrane reaches in the middle of the edge $\sigma_{\text {yield }}$ $\left(\sigma_{\text {ultimate }}=\sigma_{\text {yield }}\right)$. The maximum load $q_{\text {break }}$ for these materials is calculated here with (14) using both $\sigma_{\text {tensile }}$ and $\sigma_{\text {bend }}$ in the middle of the edge of the membrane because for nonductile (brittle) materials there is no stress regime above $\sigma_{\text {yield }}$ for plastic deformation.

For ductile metals like Al, Ni, Cu, Stainless Steel, and Ti, there is a linear relation between the strain and the applied stress up to $\sigma_{\text {yield. }}$ The membrane will not break when the pressure $q_{\text {yield }}$ is reached, and the stress in the middle of the edge may increase up to $\sigma_{\text {ultimate }}$. Between $\sigma_{\text {yield }}$ and $\sigma_{\text {ultimate }}$ the strain of the membrane strongly increases. In this region $E$ cannot be considered as a constant, in fact $E$ will diminish as a result of plastic deformation. Interpreting (14), this means that $q_{\text {break }}$ will strongly increase in this region. So, a more elongated membrane may be loaded more before it breaks, resulting in $q_{\mathrm{break}} \gg q_{\text {yield }}$. For ductile materials therefore only an under-estimate of the maximum load $q_{\text {break }}$ can be given. The under-estimate for the maximum load $q_{\mathrm{break}}$ for these materials is calculated here with (14) using only $\sigma_{\text {tensile }}$ in the middle of the edge of the membrane. For ductile materials, the local stress originating from bending will be released due to local plastic deformation (in the middle of the edge) when this local stress reaches a value above $\sigma_{\text {yield }}$.

Also, for ductile materials this under-estimate is mainly determined by the $\sigma_{\text {tensile }}$ contribution in (14). When $\sigma_{\text {yield }}$ is reached near the edge of the membrane local plastic deformation (i.e., $E$ drops) of this material will occur and the bending stress $\sigma_{\text {bend }}$ will severely reduce. 


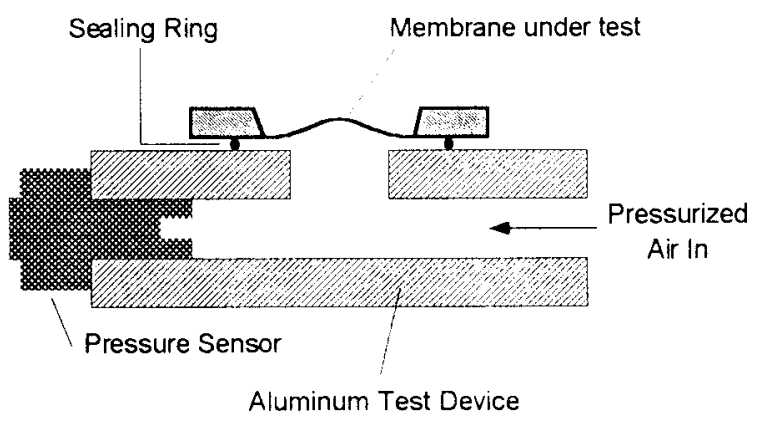

Fig. 9. Test setup.

Applying a higher load such that the lateral strain increases above $\sigma_{\text {yield }}$, the membrane will then break when $\sigma_{\text {ultimate }}$ is reached. Equation (14) is still valid although the diminished value of $E$ is not known. The under-estimate of the maximum load qbreak in this case is therefore higher than the pressure $q_{\text {tens }}$ defined as the pressure necessary for creating plastic deformation due to tensile stresses only, i.e., $q_{\text {tens }}$ is calculated from (14) leaving out $\sigma_{\text {bend }}$.

For a perforated membrane, the above equations may be used choosing a different value for $E$ and $\sigma_{\text {yield }}$. In a first-order approximation, both $E$ and $\sigma_{\text {yield }}$ are smaller and proportional with the unperforated fraction of the membrane [11]. This will result in a smaller maximum load that is also proportional to the unperforated fraction and which can be obtained from scaling equation (14) for $\sigma_{\text {total }}$.

\section{EXPERIMENTS}

To determine the maximum load of membranes, a small testdevice has been made in which membranes can be clamped (see Fig. 9). With pressurized air, the membranes can be deflected to a certain load. This maximum pressure can be measured with a pressure sensor (Honeywell, 24PC, 7Bar) connected to a digital multimeter with a peak-hold function to memorize the maximum applied pressure before fracture occurs.

\section{A. Silicon Nitride Membranes}

The dependence of the maximum load $q_{\text {break }}$ on the membrane width, membrane thickness, membrane perforation, membrane shape, and some membrane materials has been determined.

In Figs. 10-12 the dependence of the maximum load $q_{\mathrm{break}}$ on the membrane width $l$ is shown for various membrane thicknesses $h$. q break seems to be reasonably well inversely proportional to $l$ in accordance with the earlier presented theoretical equation (14).

In the three figures, straight lines have been drawn corresponding with $\sigma_{\text {yield }}=4000 \mathrm{MPa}$. These lines correspond quite well in all three figures with the data, herewith verifying that also the thickness $h$ scales according to (14).

As can be seen in Fig. 13, the maximum load of a perforated membrane is nearly two times smaller than the maximum load of an unperforated membrane. The perforations are here circular holes with a diameter of $5 \mu \mathrm{m}$. The total perforated area is

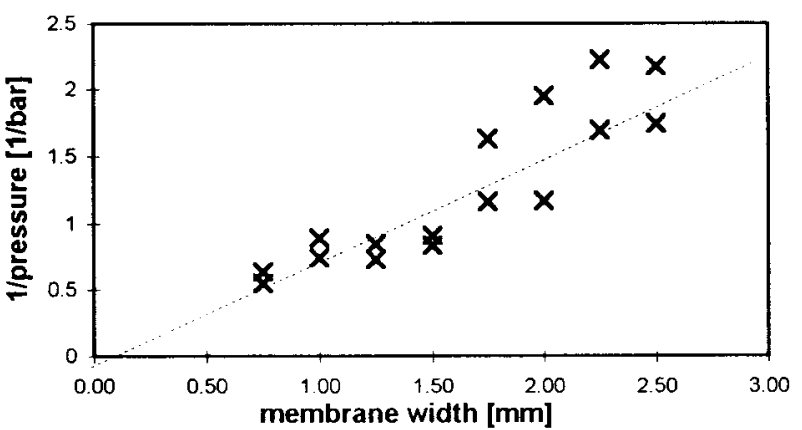

Fig. 10. Results obtained from maximum load measurements (silicon nitride membrane: $0.5 \mu \mathrm{m}$ thick) for square membranes with width $l$. Drawn line corresponds with $\sigma_{\text {yield }}=4000$.

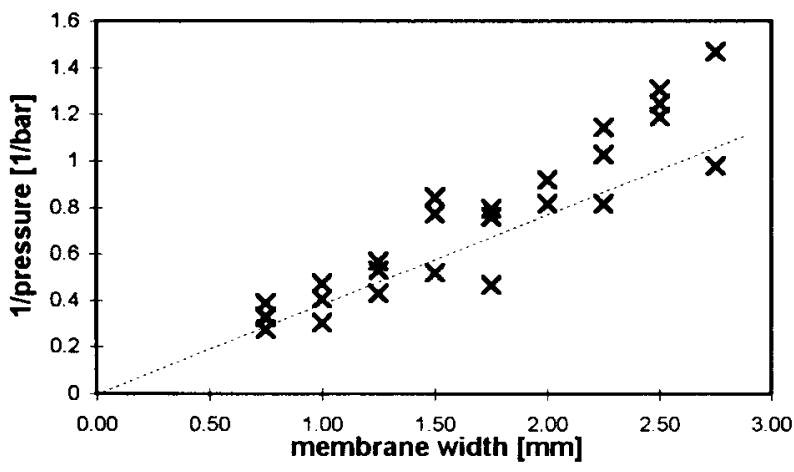

Fig. 11. Results obtained from maximum load measurements (silicon nitride membrane: $1.0 \mu \mathrm{m}$ thick) for unperforated square membranes with width $l$. Drawn line corresponds with $\sigma_{\text {yield }}=4000$.

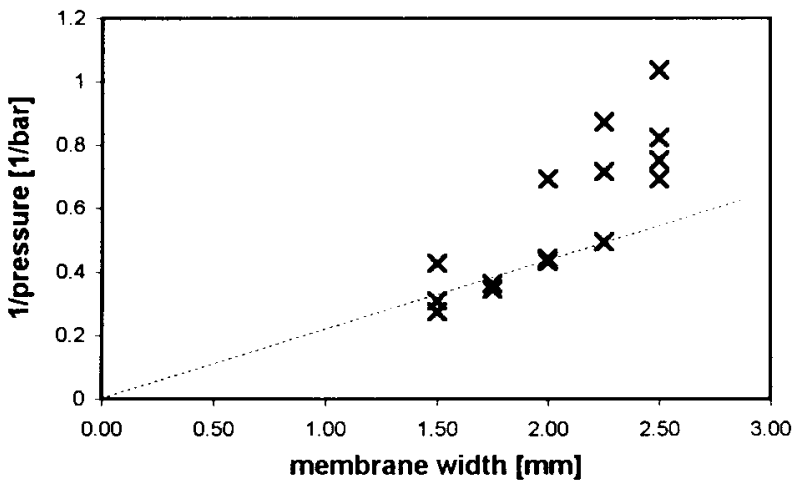

Fig. 12. Results obtained from maximum load measurements (silicon nitride membrane: $2.0 \mu \mathrm{m}$ thick) for unperforated square membranes with width $l$. Drawn line corresponds with $\sigma_{\text {yield }}=4000$.

approximately $25 \%$. The yield strength and Young's Modulus of the material silicon nitride will decrease upon perforation. If the yield strength and Young's Modulus decrease 25\% (both in first-order proportional to the perforated fraction) the estimated maximum load will decrease about $15 \%$ according to (14). The enlarged decrease of the measured maximum load (nearly $50 \%$ reduction) can not be explained herewith. Apparently, the perforated fraction is too large for a first-order approximation, second- and higher-order terms probably have a larger effect on the maximum load.

In Fig. 14 it is seen that the maximum load values are nearly constant for unperforated rectangular membranes with 


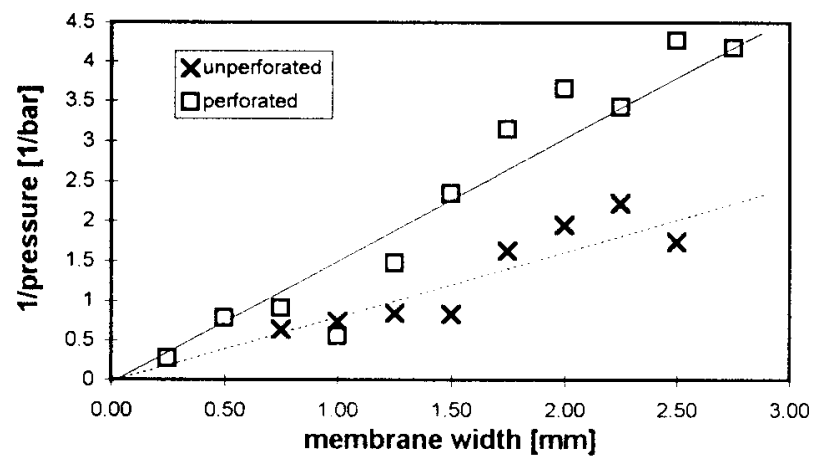

Fig. 13. Difference in maximum load of an unperforated membrane and a perforated membrane (silicon nitride membrane $0.5 \mu \mathrm{m}$ thick) for unperforated square membranes with width $l$. Drawn lines correspond to $\sigma_{\text {yield }}=4000$ $\mathrm{MPa}$ (dotted) and $\sigma_{\text {yield }}=2500 \mathrm{MPa}$ (solid).

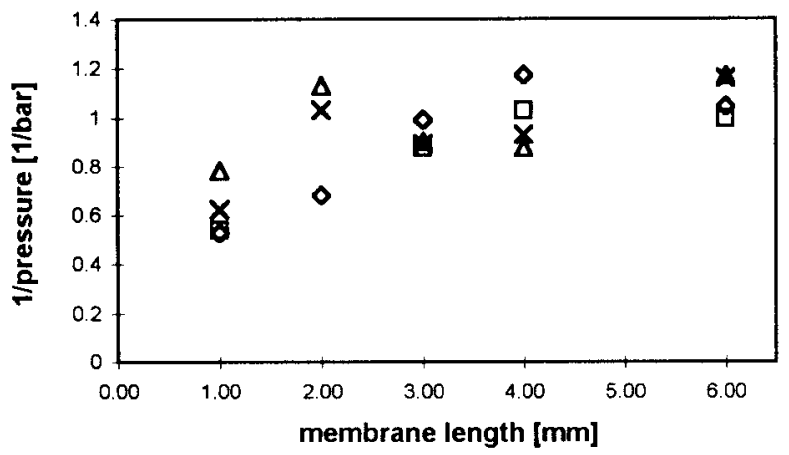

Fig. 14. Dependence on membrane shape; maximum load data of a rectangular membrane (silicon nitride, $1.0 \mu \mathrm{m}$ thick), with a fixed width of 1 $\mathrm{mm}$.

size $1 \mathrm{~mm} \times 2 \mathrm{~mm}, 1 \mathrm{~mm} \times 3 \mathrm{~mm}$, up to $1 \mathrm{~mm} \times 6$ $\mathrm{mm}$. The square membrane with size $1 \mathrm{~mm} \times 1 \mathrm{~mm}$ has a $q_{\text {break }}$ roughly $30 \%$ higher. Qualitatively this difference may easily be understood as the difference in maximum load for a membrane clamped at four edges (good model for a square membrane) and a membrane clamped at two edges (good model for a rectangular membrane with an infinite length and a fixed width; an approximating model for a square membrane).

\section{B. Ductile Membranes}

Maximum load values for breaking of the membranes of the ductile materials titanium, aluminum, and copper are depicted in Figs. 15-17. The data indicate also a linear relation between the maximum breaking load and the width $l$. As discussed in the former section for ductile materials the maximum breaking load may be much higher than the maximum load $q_{\text {yield }}$ for reaching a stress $\sigma_{\text {yield }}$ at the middle of the edge in the membrane.

In comparing the experimental found maximum breaking load for these ductile materials with the calculated $q_{\text {break }}$ as presented in Table I (membrane width $=1 \mathrm{~mm}$ ) it is found that the maximum breaking load for titanium membranes is slightly higher and that for aluminum and copper membranes it is much higher than $q_{\mathrm{break}}$. Apparently, the materials aluminum and copper have a broader plastic deformation regime than the material titanium (Fig. 18).

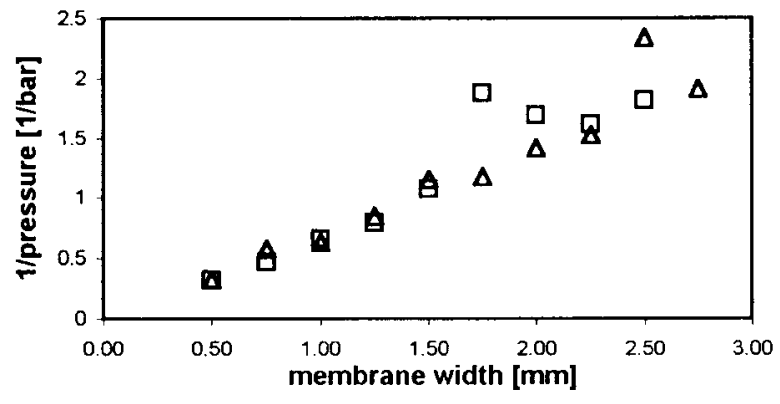

Fig. 15. Results obtained from maximum load measurements (titanium membrane: $1.0 \mu \mathrm{m}$ thick) of an unperforated square membrane with width $l$.

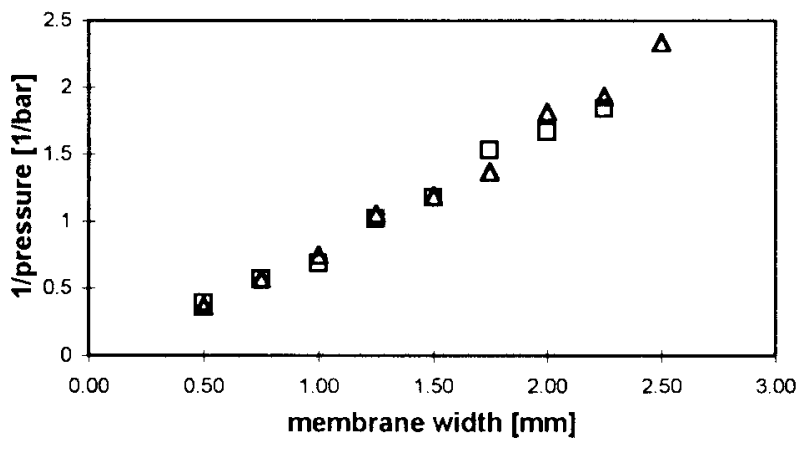

Fig. 16. Results obtained from maximum load measurements (aluminum membrane: $1.0 \mu \mathrm{m}$ thick) of an unperforated square membrane with width $l$.

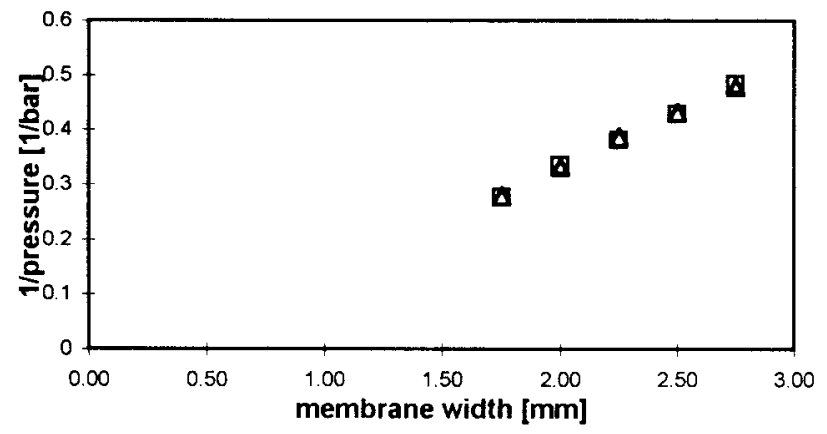

Fig. 17. Results obtained from maximum load measurements (copper membrane: $1.0 \mu \mathrm{m}$ thick) of an unperforated square membrane with width $l$. The pressure of our system ( 4 bar) was not high enough to break membranes smaller than $1.75 \mathrm{~mm}$.

\section{CONCLUSION}

Maximum load values $q_{\text {break }}$ for silicon nitride membranes have been experimentally determined by varying the width, the thickness, and the shape of the membranes. The results are in accordance with the theoretically predictions for $q_{\text {yield }}$ based on the derived formula (14). The maximum load values $q_{\text {break }}$ for perforated membranes are found to be smaller than the values for the unperforated membranes.

The maximum load values $q_{\mathrm{b} \text { reak }}$ for unperforated membranes composed of a ductile material are higher than the estimated values for $q_{\text {yield }}$. For ductile materials $q_{\text {yield }}$ may be considered as a save under-estimate for $q_{\mathrm{break}}$.

In a next study, the theory of plastic deformation will be incorporated in order to estimate more precise the maximum load value $q_{\mathrm{b} \text { reak }}$ for these materials. Also, some more results 


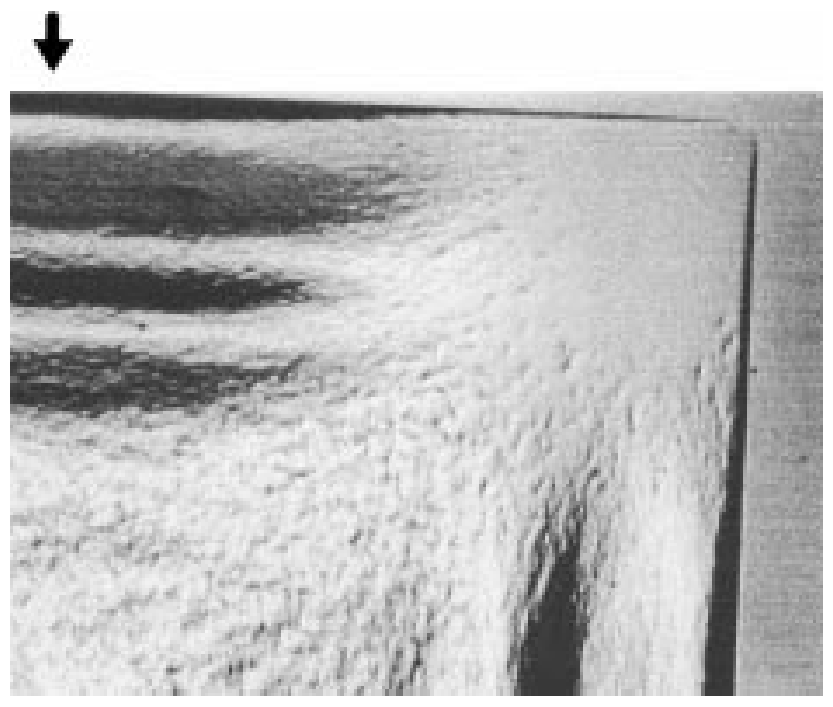

Fig. 18. An aluminum membrane $1 \mathrm{~mm} \times 1 \mathrm{~mm}$ with thickness $1 \mu \mathrm{m}$ after loading above $q_{\text {yield }}(0.03$ bar) showing plastic deformation. The arrow in the figure indicates the middle of the edge of the membrane.

on the influence of the pore size and density on $q_{\mathrm{break}}$ will be presented.

\section{ACKNOWLEDGMENT}

The authors are indebted to M. de Boer and E. Berenschot for valuable suggestions for the processing of the microsieves and to $\mathrm{H}$. Jansen for many stimulating discussions.

\section{REFERENCES}

[1] I. Porter, C. Mark, and H. Strathmann, Handbook of Industrial Membrane Technology, 1990.

[2] K. K. Chan and A. M. Brownstein, "Ceramic membranes growth prospects and opportunities," Ceramic Bull., vol. 70, pp. 703-707, 1991.

[3] C. A. Smolders, "New membrane materials and processes: A survey of work in the netherlands," Membranes, Proc. INDO Wkshp. New Delhi, India: Oxford and IBH Publishing, 1992.

[4] S. P. Timoshenko and S. Woinowsky-Krieger, Theory of Plates and Shells. New York: McGraw-Hill, ch. 1, 1959.

[5] _ Theory of Plates and Shells. New York: McGraw-Hill, ch. 12, 1959.

[6] M. P. Di Giovanni, Flat and Corrugated Diaphragm Design Handbook, Marcel Dekker, ch. 14, eq. 14.5.

[7] C. Y. Chia, Nonlinear Analysis of Plates. New York: McGraw-Hill, ch. 2, 1980.

[8] M. Heschel and S. Bouwstra, "Robust, compliant silicon nitride membranes," in Proc. MME'95, Copenhagen, Denmark, Sept. 3-5, 1995, pp. $84-87$.

[9] V. L. Spiering, S. Bouwstra, M. Elwenspoek, and J. F. Burger, J. Micromech. Microeng., vol. 3, pp. 243-246, 1993.

[10] S. Bouwstra, R. Legtenberg, and T. Popma, Sensors and Actuators, Mar. 1990, Poster Eurosensors, Nov. 88, Enschede.

[11] D. Bynum and M. M. Lemcoe, "Stresses and deflections in laterally loaded perforated plates," Welding Research Council Bull., vol. 80, 1992.

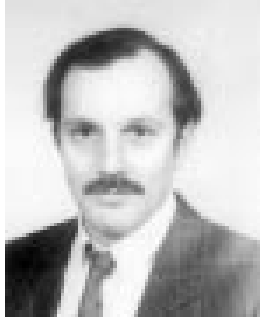

Cees van Rijn graduated from the Vrije Universiteit of Amsterdam, The Netherlands, in 1982 in physics. He received the Ph.D. degree in 1986 in nuclear magnetic relaxation of polyelectrolyte solutions from the University of Leiden, The Netherlands.

After graduation, he worked as a Scientific Engineer at Philips Eindhoven, The Netherlands, and his interests are in semiconductor technology, physical and chemical evaporation techniques, and wet and dry chemical etching. In 1991 he founded Aquamarijn Micro Filtration B.V., and he has performed research on microfiltration membranes at the MESA Research Institute, University of Twente, The Netherlands.

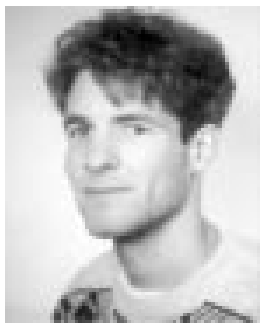

Michiel van der Wekken is a student in precision technology at the Hogeschool van Utrecht, The Netherlands. He has studied experimentally the maximum load of membranes during a practical trainee at the MESA Research Institute, University of Twente, The Netherlands.

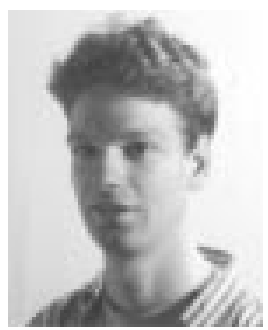

Wietze Nijdam received the M.Sc. degree from the University of Twente, The Netherlands, in 1995 (electrical engineering). His thesis dealt with a device for blood plasma separation. After graduation, he became a Research Scientist at Aquamarijn Micro Filtration B.V., where he is involved in membrane fabrication.

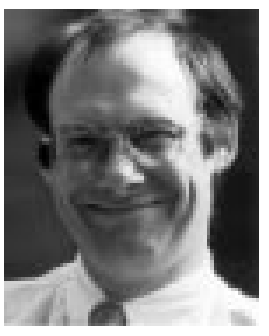

Miko Elwenspoek graduated from Freie Universität Berlin, Germany, in 1977 (physics of liquids). He received the Ph.D. degree in 1983 (nuclear quadrupolar relaxation in liquid alloys) from the same University.

From 1983 to 1987 he did research on crystal growth of organic materials from melt and solution at University of Nijmegen, The Netherlands. Since 1987 has been Head of the Micromechanics Department at the University of Twente, and since 1996 he has been a Professor in the faculty of Electrical Engineering. His research interests include device physics, microactuators, microsensors, microsystems, and etching mechanism and technology.

Dr. Elwenspoek is a member of the MME (Micro Mechanics Europe) Steering Committee and the Journal of Microelectromechanical Systems Steering Committee. 